\title{
USO DA INTERNET E OPORTUNIDADES DE PARTICIPAÇÃO POLÍTICA VIRTUAL NAS ELEIÇÕES MUNICIPAIS DE OUTUBRO DE 2008 NO BRASIL
}

\author{
Sérgio Braga \\ María Alejandra Nicolás \\ Andressa Silvério Terrona França
}

\begin{abstract}
Resumo
O objetivo deste artigo é refletir sobre o uso da internet nas eleições brasileiras a partir dos resultados de nossa pesquisa empírica sobre o emprego das novas tecnologias pelos 175 candidatos às prefeituras municipais das capitais brasileiras nas eleições de outubro de 2008. Utilizando técnicas de análise de conteúdo a partir dos modelos desenvolvidos anteriormente por Ferber, Foltz e Puglize (2007) e Braga, Nicolás e França (2010) para detectar padrões de uso da web pelos candidatos e mapear as oportunidades de interação propiciadas pela internet entre candidatos e eleitores, chegamos a dois resultados básicos: (i) existência de um "digital divide" entre os candidatos de diversas regiões e com diferentes graus de escolaridade e patrimônio; (ii) baixa difusão do uso das chamadas "redes sociais" pelos candidatos, e mesmo de mecanismos tradicionais de interação como blogs, fóruns e chats. Entretanto, embora as ferramentas da "Web 2.0" tenham sido pouco utilizadas no último pleito para as capitais brasileiras, a internet deu lugar a algumas experiências embrionárias de participação política que nos permitem antever os potenciais dessa mídia para alterar significativamente as relações entre candidatos e opinião pública nos próximos pleitos municipais brasileiros.
\end{abstract}

Palavras-chave: Eleições Municipais Brasileiras de 2008; Participação Política Online; Novas Tecnologias e Eleições; Representação Política.

\begin{abstract}
The aim of this paper is to present the results of our research about the use of Internet for candidates of the 175 municipalities of the Brazilian capitals in the 2008 elections, giving the results of our content analysis of virtual interaction tools used by candidates for mayor in these municipalities. Using content analysis techniques based on models earlier elaborated by Ferber, Foltz and Puglize (2007) and Braga, Nicolas and França (2010) to detect patterns of Web use by candidates and mapping different modalities of interaction afforded by the Internet between candidates and voters, we arrive at two basic findings: (i) the existence of a "digital divide" between candidates from different regions and with varying degrees of education and wealthy; (ii) low diffusion of the use of "social networks" by the candidates, and even traditional mechanisms of interaction such as blogs, forums and chats. However, although the tools of "Web 2.0" have been little used in the last election for state capitals, the internet has given rise to some embryonic experiences of political participation that enable us to foresee the potential of this medium to significantly alter the relationship between candidates and opinion public in the coming municipal elections in Brazil.
\end{abstract}


Keywords: Brazilian Municipal Elections of 2008; Political Participation Online; New Technologies and Elections; Political Representation.

\section{Introdução: internet, eleições e participação política}

(NTICs) em finais do século $X X$ e seu posterior desenvolvimento e massificação nos últimos anos vem suscitando amplos debates acerca de seu papel nas sociedades contemporâneas e, mais particularmente, sobre seus impactos nas democracias parlamentares e eleitorais. Teóricos de vários matizes, gestores públicos e analistas da imprensa têm disseminado a idéia de que essas novas tecnologias, principalmente a internet, ao abrir canais de comunicação e interação mais práticos e econômicos modificarão substancialmente a forma como as pessoas se relacionam em várias dimensões de sua vida social. A política, como parte integrante do conjunto das relações sociais, também não deixaria de sofrer sua influência.

Expressando este interesse cada vez maior dos estudiosos sobre os impactos da internet nos processos de representação política e nos sistemas políticos contemporâneos de uma maneira geral, a questão do uso das NTICs nas democracias representativas vem suscitando uma produção científica expressiva, que busca analisar os variados usos da web pelos diferentes atores e instituições que integram o "sistema político virtual" das democracias representativas contemporâneas (órgãos governamentais, parlamentos, candidatos às eleições, parlamentares, partidos políticos, bem como movimentos sociais), e suas repercussões nas formas de ação coletiva e de comportamento político de tais atores (NORRIS, 2001; CHADWICK e HOWARD, 2008).

Para fins do presente texto interessa-nos especificamente, dentro desse quadro mais geral, os estudos dedicados a analisar o uso da internet pelos candidatos em campanhas eleitorais.

\section{Papel das novas tecnologias nas eleições: a literatura internacional e brasileira}

Inicialmente, devemos mencionar a existência de uma bibliografia crescente, especialmente nos EUA e no continente europeu, sobre o uso dos recursos propiciados pelas novas tecnologias e pela internet (websites, blogs, os diversos tipos de mídias e redes sociais etc.) durante as campanhas eleitorais (DAVIS, 1999; IRELAND e NASH, 2001; BIMBER e DAVID, 2003; CORNFIELD, 2004; TRIPPI, 2004; COHEN, 2006; PARKIN, 2007; GAINOUS e WAGNER, 2009; CHADWICK e HOWARD, 2008; GOMES e AGGIO, 2009). Dentro desse quadro, podemos observar o aparecimento, também no Brasil, de uma série de estudos mais sistemáticos e empiricamente orientados 
(diferente dos meros comentários avaliativos ocasionais e com ambições "normativas" veiculados por certos analistas na grande imprensa) dedicados a analisar o papel das novas tecnologias nos pleitos eleitorais, destacando-se especialmente os que têm por objeto de estudo os usos da internet, comunidades virtuais tais como Orkut e, mais recentemente, as novas mídias sociais pelos candidatos às eleições majoritárias, especialmente eleições presidenciais.

A esse respeito, podemos mencionar um primeiro grupo de estudos que partem da ótica mais estrita do sociólogo e do cientista político interessado nos múltiplos aspectos do uso da internet por candidatos nas democracias representativas (FERNANDEZ, 2005; IASULAITIS, 2007; BRAGA, CRUZ e FRANÇA, 2007; BRANDÃO e BATISTA, 2007; BRANDÃO JR., 2008; BRAGA, NICOLÁS e FRANÇA, 2010). Essa vertente de estudos, partindo de conceitos mais próximos à sociologia política, visa à apreensão do impacto da internet no funcionamento de dimensões relevantes das democracias parlamentares e no estreitamento dos vínculos entre elites dirigentes e cidadãos comuns, geralmente relacionando a atuação dos candidatos por intermédio da internet com outros fenômenos existentes no mundo off-line de interesse do cientista político stricto sensu, tais como conexão eleitoral, clientelismo, perfil socioeconômico dos candidatos e eventual existência de uma fratura digital (digital divide) entre os diversos subgrupos de postulantes ao pleito eleitoral.

Outra vertente de estudos mais próxima à ótica da comunicação política busca examinar o uso da internet nas campanhas eleitorais, geralmente analisando sua relação com outras mídias tradicionais. Destacamse a esse respeito os trabalhos de Aldé e Borges (2004) sobre o papel das home pages dos candidatos presidenciais às eleições de 2002 na construção da pauta dos órgãos da grande mídia e os de Chaia (2007) e Coutinho e Safatle (2009) que examinam o uso de comunidades virtuais tais como Orkut e congêneres como espaço de debates dos cidadãos durante as campanhas eleitorais.

Com efeito, tentativas recentes de sistematização bibliográfica indicam que este tipo de estudo ainda está em seu início no Brasil, embora já haja um corpus relativamente amplo de trabalhos relevantes sobre a temática mais geral dos impactos e dos usos da internet nas eleições na literatura internacional (GOMES e AGGIO, 2009; AGGIO, 2010) ${ }^{1}$.

A esse respeito, talvez possamos afirmar que os prognósticos e

\footnotetext{
${ }^{1}$ Para os autores, existem três estágios no uso da internet pelos políticos: (i) "pré-web", que concentra o uso da internet no envio de mensagens eletrônicas e emails, sem um uso interativo dos websites por parte dos políticos; (ii) um estágio "Web", que tem como plataforma básica de contato dos políticos com o público em geral os websites pessoais, basicamente reproduzindo os conteúdos das mídias tradicionais; (iii) e uma terceira etapa iniciada com a campanha presidencial de Barack Obama, qualificada de "pós-web", onde os websites passam a ser apenas uma ferramenta virtual entre outras empregadas pelos políticos, cumprindo a função de ser um distribuidor de conteúdo a ser reproduzido nas mídias sociais.
} 


\section{DOSSIÊ OPINIÃO PÚBLICA, ELEIÇÕES E PARTICIPAÇÃO POLÍTICA NAS DEMOCRACIAS CONTEMPORÂNEAS}

avaliações de diversos analistas sobre o emprego das novas tecnologias e da internet nas eleições brasileiras reproduzem, mutatis mutandis, o debate mais geral sobre o impacto das NTICs nos sistemas políticos contemporâneos que se trava desde pelo menos meados da década de 1990 nos países de democracia mais institucionalizada e com maiores percentuais do eleitorado com acesso às tecnologias digitais (NORRIS, 2001). Como se sabe, antes do "fenômeno Obama" este debate se estruturava em torno dos potenciais da Web de gerar novas formas de democracia, para além das democracias representativas realmente existentes, dando origem a uma polarização radical entre os "ciberpessimistas" ou "cibercéticos" - para os quais a internet pouco altera as formas tradicionais de fazer política, apenas reproduzindo a "política como usual" (MARGOLIS e RESNICK, 2000) e os "ciberotimistas" mais exultantes - para os quais a internet seria capaz de gerar novas formas de democracia "deliberativa, "direta", ou "participativa" capazes mesmo de promover uma superação histórica, no longo prazo, das formas de democracia representativa realmente existentes.

A diferença agora, após a experiência política propiciada pela campanha eleitoral e por algumas iniciativas implementadas durante a primeira fase do governo Obama (onde os recursos das novas tecnologias e da Web 2.0 foram amplamente empregados para dinamizar as instituições mais tradicionais das poliarquias, tais como a participação e a competição no processo de escolha de elites políticas alternativas - e não para criar um novo "modelo de democracia" substancialmente diferente dos modelos de democracia parlamentares geralmente existentes), reside em que o debate parece estar focado em questões com maior rendimento analítico do ponto de vista do observador político, e mais estimulantes do ponto de vista dos estrategistas de campanha, tais como: quais os potenciais das NTICs de tornarem mais participativas as instituições-chave da democracias parlamentares realmente existentes (partidos, parlamentos, eleições etc.) abrindo novos espaços de deliberação política para a opinião pública e de engajamento cívico dos cidadãos? Como a internet pode agregar valor às campanhas eleitorais, dinamizando e tornando mais eficazes os vários processos que as constituem? Qual a possibilidade do "fenômeno Obama" vir a se repetir em outros contextos histórico-institucionais e culturais e com que grau de intensidade? Como, em suma, os novos recursos possibilitados pela Web 2.0 e penas novas tecnologias digitais podem reconfigurar e reformatar o funcionamento de algumas instituições-chave das democracias representativas, especialmente as campanhas eleitorais?

O objetivo deste artigo é contribuir com o avanço das investigações sobre o uso da Web nos pleitos eleitorais no Brasil e nos situar dentro do debate travado pelos estudos anteriores, especialmente sobre o uso das novas tecnologias nos pleitos eleitorais brasileiros. Sublinhe-se ainda que não é nosso objetivo examinar os impactos das ferramentas digitais na decisão de voto do eleitor, mas sim realizar um mapeamento das oportunidades de 
participação disponibilizadas pelos candidatos em seus websites a fim de apresentar subsídios para estudos longitudinais mais aprofundados a serem efetuados em outros pleitos, especialmente as campanhas municipais que é o tema central deste estudo.

A partir deste objetivo geral, buscaremos cumprir os seguintes objetivos específicos:

a) em primeiro lugar, detectar alguns padrões de uso da web pelos candidatos às eleições majoritárias para as chefias do Executivo em 26 unidades da federação brasileiras no pleito de outubro de 2008;

b) em segundo lugar, efetuar uma breve análise de conteúdo dos websites dos candidatos a prefeito nas capitais brasileiras a fim de verificar que tipo de recurso foi por eles utilizado em tais sites e com qual grau de intensidade;

c) por fim, buscaremos inventariar alguns mecanismos de interação entre candidatos e opinião pública disponibilizados a partir de tais websites. Procuraremos demonstrar a proposição segundo a qual, apesar das restrições da legislação eleitoral brasileira, alguns mecanismos mais sofisticados de interação e participação política foram difundidos através dos websites eleitorais dos candidatos, embora sem dar origem a práticas inovadoras que reproduzissem de alguma forma os espetaculares resultados obtidos, por exemplo, por Barack Obama no pleito estadunidense de $2008^{2}$.

Para cumprir tais metas organizaremos nossa exposição da seguinte forma: 1) Inicialmente, extrairemos da bibliografia relevante alguns parâmetros analíticos que estruturarão a análise efetuada a seguir, apresentando as linhas gerais do modelo de interatividade empregados por Ferber, Foltz e Puglise (2007) e Lilleker e Jackson (2009) em suas análises; 2) Em seguida, apresentaremos a metodologia empregada e as categorias básicas que utilizamos para empreender a análise de conteúdo dos websites; 3) Nos próximos itens, apresentaremos os resultados da pesquisa, fornecendo evidências sobre o tipo e a intensidade do uso das ferramentas digitais por categorias de candidatos; 4) Por fim, indicaremos as principais experiências de interação política entre candidatos e eleitores ocorridas na web e extrairemos algumas implicações mais gerais da análise efetuada anteriomente.

\footnotetext{
2 Procuraremos fazer um inventário sistematizado dos principais argumentos produzidos por diferentes autores acerca dos principais obstáculos ao uso da internet como ferramenta eficaz de mobilização nos pleitos eleitorais brasileiros em moldes análogos aos observados nos EUA em Braga (2010). Esclareça-se também que utilizamos como unidade básica de investigação os websites oficiais dos candidatos registrados no TSE na medida em que partimos do pressuposto que são os websites as plataformas mais importantes a partir das quais os candidatos estruturam suas campanhas virtuais. Nossa ferramenta de busca básica foi o Google, na medida em que verificamos que muitas vezes um determinado candidato registrava um site no registro.com, mas não o mantinha online com regularidade.
} 


\section{O modelo de interação de Ferber e os vários cenários de discussão pública}

Para estruturar nossa análise dos mecanismos de interação e participação política nos websites dos candidatos às prefeituras municipais no pleito de outubro de 2008, procuraremos aplicar uma versão ligeiramente modificada do modelo de interatividade formulado por Ferber, Foltz e Puglise (2007) no estudo dos mecanismos de interação entre elites políticas e cidadãos ordinários propiciados pelas novas tecnologias, especialmente a internet. Esses autores chamam a atenção para o fato de que a introdução das ferramentas da "Web 2.0" como alguns tipos de blogs, chats, comunidades virtuais e redes sociais ensejaram o estudo de novas formas de comunicação, diferentes das geradas pelas aplicações da "Web 1.0" que se apóiam em processos mais verticalizados de transferência de informações. Além dos modelos de comunicação de duas vias, Ferber, Foltz e Puglise (2007, p. 393) propõem "a three-way model of communication", mais apropriado para encorajar a deliberação pública (o que não equivale dizer que ela se concretize necessariamente nos websites dos candidatos). 0 autor utilizou o modelo quadripartido de ciber-interatividade de McMillan (2002) e construiu "a six-part model of Cyber-Interactivity" (FERBER, FOLTZ e PUGLISE, 2007, p. 393), conforme demonstrado na figura abaixo:

Figura 1 - Modelo de Interatividade (adap. Ferber, Foltz e Puglise, 2007)

Revised user-to-user interactivity model

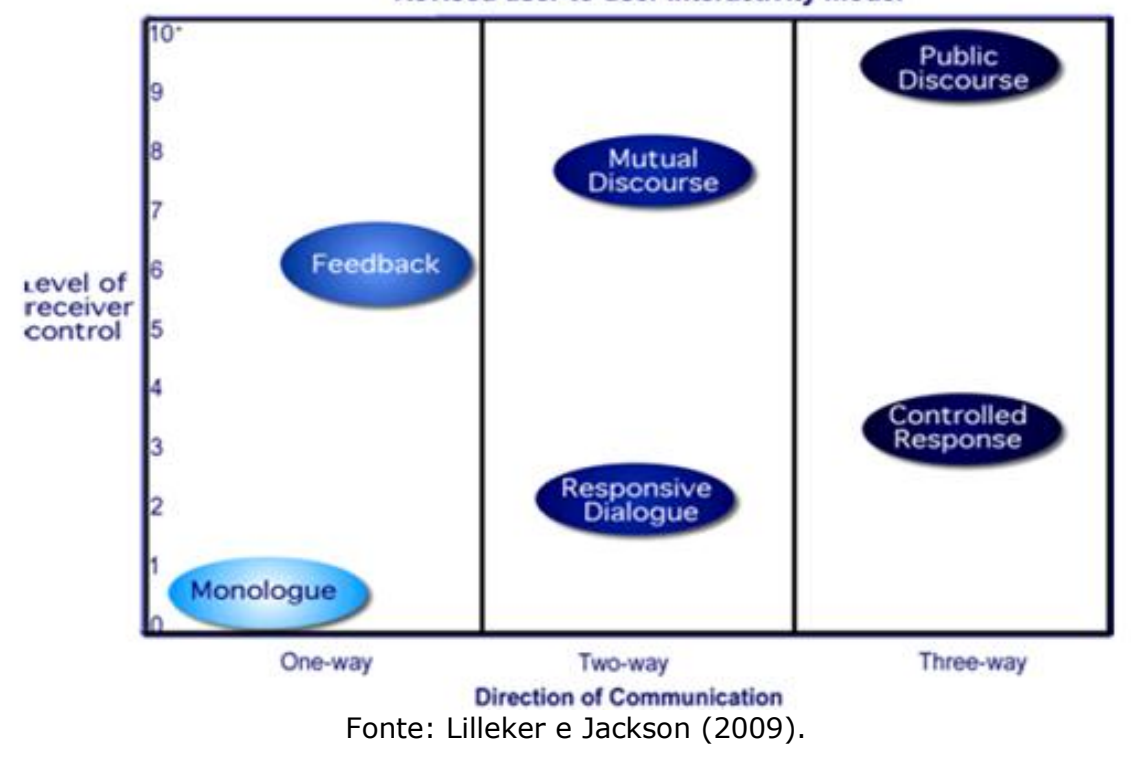

Portanto, segundo os autores, podemos enumerar os seguintes contextos de interação entre emissor e receptor das mensagens na internet, 
acompanhados dos respectivos meios correspondentes de difusão das mensagens:

Quadro 1 - Contextos de interação, mídias específicas e experiências de interação nos websites dos candidatos

\begin{tabular}{|c|c|c|c|}
\hline & Tipo de Interação & Relação entre os atores & Meio apropriado \\
\hline & & & \\
\hline 1 & Monólogo & 1 via com baixo controle de $R$ & $\begin{array}{l}\text { Informações } \\
\text { disponibilizadas nos } \\
\text { websites; divulgação de } \\
\text { material de propaganda da } \\
\text { instituição; Newsletter } \\
\end{array}$ \\
\hline 2 & Feedback & $\begin{array}{l}1 \text { via com maior } \\
\text { controle/participação do receptor }\end{array}$ & $\begin{array}{l}\text { Formulários de E-mail; Blog } \\
\text { atualizado que não permite } \\
\text { comentários }\end{array}$ \\
\hline 3 & Diálogo Responsivo & $\begin{array}{l}2 \text { vias, mas o emissor detém } \\
\text { maior controle sobre o processo }\end{array}$ & $\begin{array}{l}\text { Enquetes; Sondagens de } \\
\text { opinião e surveys aos } \\
\text { eleitores; possibilidade de } \\
\text { comentar notícias }\end{array}$ \\
\hline 4 & Discurso Mútuo & $\begin{array}{l}2 \text { vias mas com maior controle } \\
\text { dos receptores/participantes } \\
\text { sobre o processo de interação }\end{array}$ & $\begin{array}{l}\text { Blogs que permitem } \\
\text { comentários; mural de } \\
\text { mensagens }\end{array}$ \\
\hline 5 & Resposta controlada & $\begin{array}{l}3 \text { vias, mensagens são } \\
\text { publicizadas, mas o emissor } \\
\text { detém elevado grau de controle } \\
\text { sobre as mensagens }\end{array}$ & $\begin{array}{l}\text { Fóruns e chats moderados; } \\
\text { sugestão de propostas de } \\
\text { governo }\end{array}$ \\
\hline 6 & Discurso Público & $\begin{array}{l}3 \text { vias, mensagens são } \\
\text { publicizadas, mas com baixo } \\
\text { grau de controle do emissor } \\
\text { possibilitando um processo } \\
\text { deliberativo mais abrangente }\end{array}$ & $\begin{array}{l}\text { Facebook; Twitter; fóruns e } \\
\text { chats não moderados; } \\
\text { canais abertos do Youtube } \\
\text { e outras mídias que } \\
\text { permitem postagem com } \\
\text { baixo grau de controle do } \\
\text { gestor da plataforma }\end{array}$ \\
\hline
\end{tabular}

Fonte: Elaboração própria a partir de Ferber, Foltz e Puglise (2007).

A partir das categorias acima pretendemos utilizar o modelo proposto por Lilleker e Jackson (2009), que utilizam duas variáveis para revisar o modelo clássico de interatividade na web: i) nível de controle do público; ii) direção da comunicação. Note-se que o modelo não é utilizado para apreender os graus de deliberação ocorridos nos espaços virtuais, mas sim as possibilidades de interação entre vários atores, bem como o grau de controle do emissor das mensagens sobre os contextos de interação, o que ao menos hipoteticamente abre maiores possibilidades de participação para o cidadãointernauta. Sendo assim, a partir das considerações mais gerais e dos "insights" de Lilleker e Jackson (2009) e de Ferber e seus colaboradores, 


\section{DOSSIÊ OPINIÃO PÚBLICA, ELEIÇÕES E PARTICIPAÇÃO POLÍTICA NAS DEMOCRACIAS CONTEMPORÂNEAS}

assim como da metodologia de análise de conteúdo delineada no próximo item, buscaremos efetuar um mapeamento preliminar e abrangente dos mecanismos de interação entre candidatos à prefeitura das capitais brasileiras no pleito de outubro de 2008.

\section{Metodologia de análise}

Antes de entrar na análise dos mecanismos de interação disponíveis nos websites eleitorais dos candidatos (doravante referidos como WEC), convém empreender um exame de cunho mais quantitativo dos recursos disponíveis nos mesmos. Assim procederemos porque, embora nosso objetivo principal seja o de analisar a presença dos vários mecanismos de interação e participação existentes nos WEC (na medida em que partimos do princípio de que, no contexto brasileiro, é na disponibilização de tais ferramentas que a internet pode agregar mais valor às campanhas eleitorais, mais do que, por exemplo, como instrumento de arrecadação de recursos, mobilização ou alteração significativa de resultados eleitorais), o rendimento analítico desse objetivo de ordem geral se complementa com a necessidade de mapear outras dimensões que consideramos relevantes na atuação política dos candidatos em seus websites e que dizem respeito a aspectos do funcionamento das instituições democráticas.

Para mensurar o grau de intensidade da presença destes elementos nos websites examinados, procuramos elaborar um indicador que expressasse sinteticamente o grau de uso de cada dimensão, que nos possibilitou a apreensão sintética da maior ou menor amplitude de frequencia das variáveis que são objeto de exame no texto. A partir da bibliografia listamos uma série de itens potencialmente presentes nos WECs e que consideramos relevantes para os fins e enquadramentos teóricos da presente pesquisa ${ }^{3}$. A pontuação máxima corresponde a um website hipotético que, em tese, conteria todos os itens classificados. Dada a grande quantidade de websites analisados, procuramos diminuir o número de variáveis para aumentar a magnitude do campo de observação.

Os elementos mapeados foram reagrupados em seis categorias, cada uma correspondente a uma função ou dimensão do uso dos recursos da internet para agilizar os fluxos de comunicação e informação existentes nos websites:

1-Navegabilidade/acessibilidade: são recursos nos websites de

\footnotetext{
${ }^{3}$ Dentre os textos que se propuseram a efetuar content analysis (análise de conteúdo) de WECs, destacamos a tese de mestrado de Rodrigo Fernandez sobre os candidatos às eleições majoritárias de 2000 a 2004 (FERNANDEZ, 2005) e o de Sylvia Iasulaitis (2007), sobre a campanha presidencial de 2006. Sublinhe-se que ambos os estudos estão bastante influenciados pelo modelo sugerido por Gibson e Ward (2003), elaborado num contexto que poderíamos denominar "pré Web 2.0".
} 
candidatos que estimulam o primeiro contato do internauta com o site, ou seja, mecanismos de navegação oferecidos aos visitantes.

2-Informação: São informações básicas dos candidatos, que permitem ao internauta ter um conhecimento sobre o candidato. Incluímos desde a biografia, trajetória política, legenda partidária até informação sobre os comitês de campanha.

3-Comunicação e mídia: ferramentas de informação mais refinadas através de arquivos sonoros, vídeos e imagens, que geralmente reproduzem no espaço virtual recursos de comunicação existentes fora dele.

4-Participação e "falas cidadãs": são dispositivos que permitem a manifestação dos discursos e formas de expressão dos internautas através de diversas ferramentas, tais como postagens, envio de fotos e vídeos etc.

5-Mobilização e integração em rede: são informações que dizem respeito à prestação de contas da candidatura, desde lista de doações até funcionários trabalhando na campanha. Também incluímos nesse item informações mais substantivas sobre a candidatura e programas de governo ou propostas, e ferramentas de estímulo a um engajamento mais ativo dos cidadãos nas campanhas eleitorais.

6-Redes sociais e ferramentas Web 2.0 mais recentes: nesse item incluímos as novas tecnologias mais recentes e ferramentas de construção de redes sociais, tais como Twitter, Facebook, canais do Youtube, comunidades virtuais e acervo de fotos disponibilizados na $W e b$.

Cabe ainda sublinhar que não elaboramos nenhum indicador mais detalhado ponderando as variáveis segundo sua importância relativa para a estruturação dos websites, como o fizemos em estudos anteriores (BRAGA, 2007; BRAGA e NICOLAS, 2008), mas apenas calculamos os percentuais de presença de cada um dos itens nos WECs. Deve-se mencionar, no entanto, que, ao contrário de outros estudos, não apenas verificamos a presença ou ausência de cada uma das variáveis nos websites, mas também testamos a funcionalidade da maior parte delas. Como não atribuímos nenhum fator de ponderação aos itens pesquisados, mas apenas calculamos seus percentuais de presença, isso implica que atribuímos valores equivalentes a todos as variáveis examinadas, tendo em vista que o objetivo final de nossa análise era mapear os mecanismos de interação e participação mais avançados disponibilizados em tais plataformas.

\section{Análise dos resultados}

$\mathrm{Na}$ apresentação dos resultados de nossa pesquisa seguiremos o seguinte percurso: a) inicialmente forneceremos algumas evidências sobre o perfil dos usuários e não-usuários de websites na campanha eleitoral de outubro de 2008; b) em segundo lugar, apresentaremos nossa análise da presença dos recursos utilizados pelos candidatos em seus websites no pleito 
eleitoral; c) por fim, destacaremos algumas das experiências mais significativas de interação política disponibilizadas a partir dos WECs, bem como sua intensidade de uso ocorridas no último pleito.

\subsection{Quem esteve e que não esteve online: perfil dos usuários e não- usuários de websites}

Antes de entrarmos no exame propriamente dito do uso da web pelos candidatos a prefeito nas eleições de outubro de 2008 nas capitais brasileiras, convém apresentarmos algumas evidências empíricas sobre o uso da internet pelos deferentes subgrupos de candidatos. Essa apresentação preliminar de alguns números tem como objetivo - além de nos afastar das análises excessivamente abstratas e especulativas sobre o uso da web em campanhas eleitorais - verificar duas proposições básicas: a) se há indícios ou não da existência de algum "digital divide" ou "social divide" do uso da internet em campanhas eleitorais no Brasil; b) verificar se o uso da internet está associado com o perfil social, experiência política ou recursos políticos prévios possuídos pelos diferentes candidatos.

Os dados sobre o percentual de uso de website pelos candidatos nas 26 capitais brasileiras nos é dado pelo gráfico abaixo:

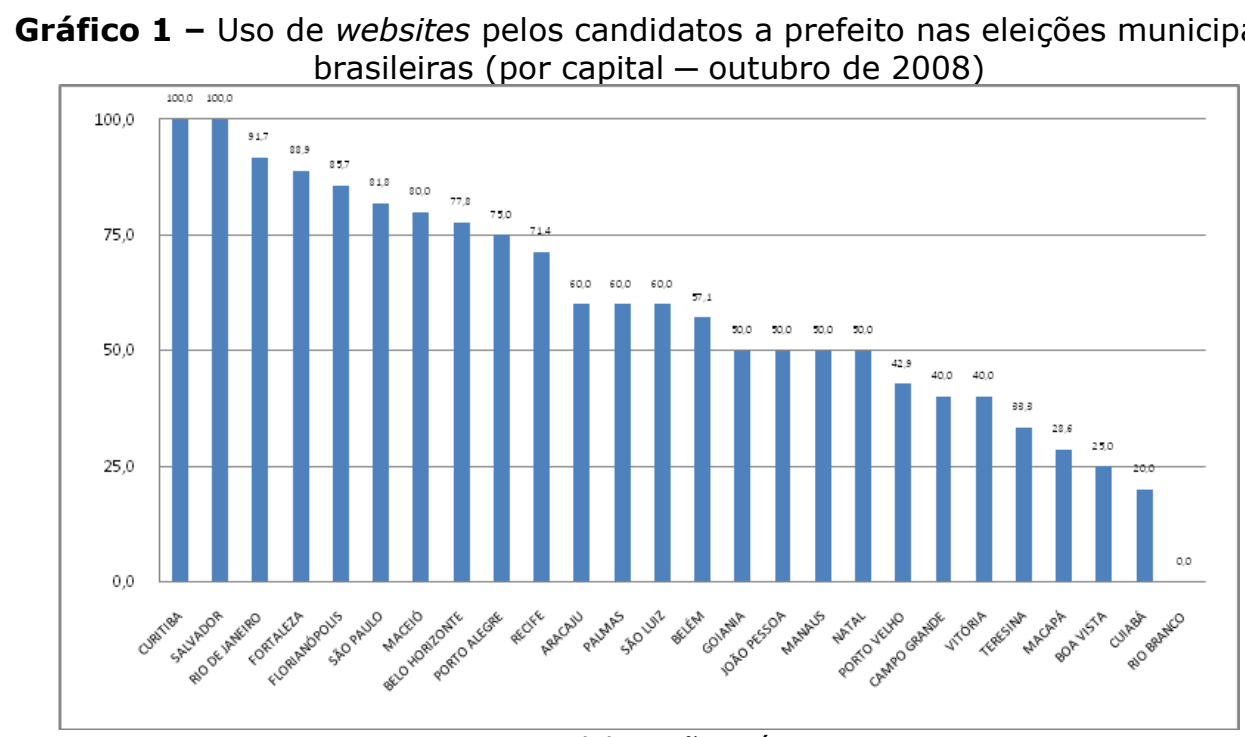

Fonte: Elaboração própria.

Como se pode ver pelo gráfico acima, as cidades que tiveram mais candidatos utilizando website na campanha eleitoral foram Curitiba (PR) e Salvador (BA), seguidas pelo Rio de Janeiro (RJ), Fortaleza (CE), São Paulo $(\mathrm{SP})$ e Maceió (AL). Das 26 capitais brasileiras analisadas, apenas 9 (34\%) 
apresentaram altos percentuais de candidatos usuários de websites. Com exceção de Vitória (ES) todas as demais capitais das regiões sul e sudeste do Brasil possuíam alto percentual de candidatos que investiram em campanhas online, sendo que nenhuma das capitais das regiões norte e centro-oeste do Brasil se inclui nesse grupo.

Isso nos permite observar a existência de um "digital divide" no Brasil (embora não tão linear e sujeito a exceções, como pode ser visualizado pelo gráfico acima), fato que pode ser melhor ilustrado pela tabela abaixo, onde cruzamos os dados de existência de campanha online com as diferentes regiões originárias dos candidatos às prefeituras.

Tabela 1 - Candidatos com e sem website (por região)

\begin{tabular}{l|c|c|c|c|c|c}
\hline & \multicolumn{2}{|c|}{ Com website } & \multicolumn{2}{c|}{ Sem website } & \multicolumn{2}{c}{ Total } \\
\hline & $\mathrm{N}$ & $\%$ & $\mathrm{~N}$ & $\%$ & $\mathrm{~N}$ & $\%$ \\
\hline Sul & 20 & 87,0 & 3 & 13,0 & 23 & 100,0 \\
\hline Sudeste & 29 & 78,4 & 8 & 21,6 & 37 & 100,0 \\
\hline Nordeste & 40 & 65,6 & 21 & 34,4 & 61 & 100,0 \\
\hline Norte & 16 & 40,0 & 24 & 60,0 & 40 & 100,0 \\
\hline Centro-oeste & 5 & 35,7 & 9 & 64,3 & 14 & 100,0 \\
\hline & $\mathbf{1 1 0}$ & $\mathbf{6 2 , 9}$ & $\mathbf{6 5}$ & $\mathbf{3 7 , 1}$ & $\mathbf{1 7 5}$ & $\mathbf{1 0 0 , 0}$ \\
\hline
\end{tabular}

Pelos dados da tabela, verificamos que as regiões sul ( $87 \%)$ e sudeste $(78,4 \%)$ apresentam percentuais quase exatamente simétricos às regiões norte $(40 \%)$ e centro-oeste $(35,7 \%)$, observando-se uma forte associação agregada entre IDH médio da região e percentual de candidatos com website.

Em relação aos partidos políticos e corrente ideológico-programática, os dados são informados no gráfico e na tabela abaixo. 
DOSSIÊ OPINIÃO PÚBLICA, ELEIÇÕES E PARTICIPAÇÃO POLÍTICA NAS DEMOCRACIAS CONTEMPORÂNEAS

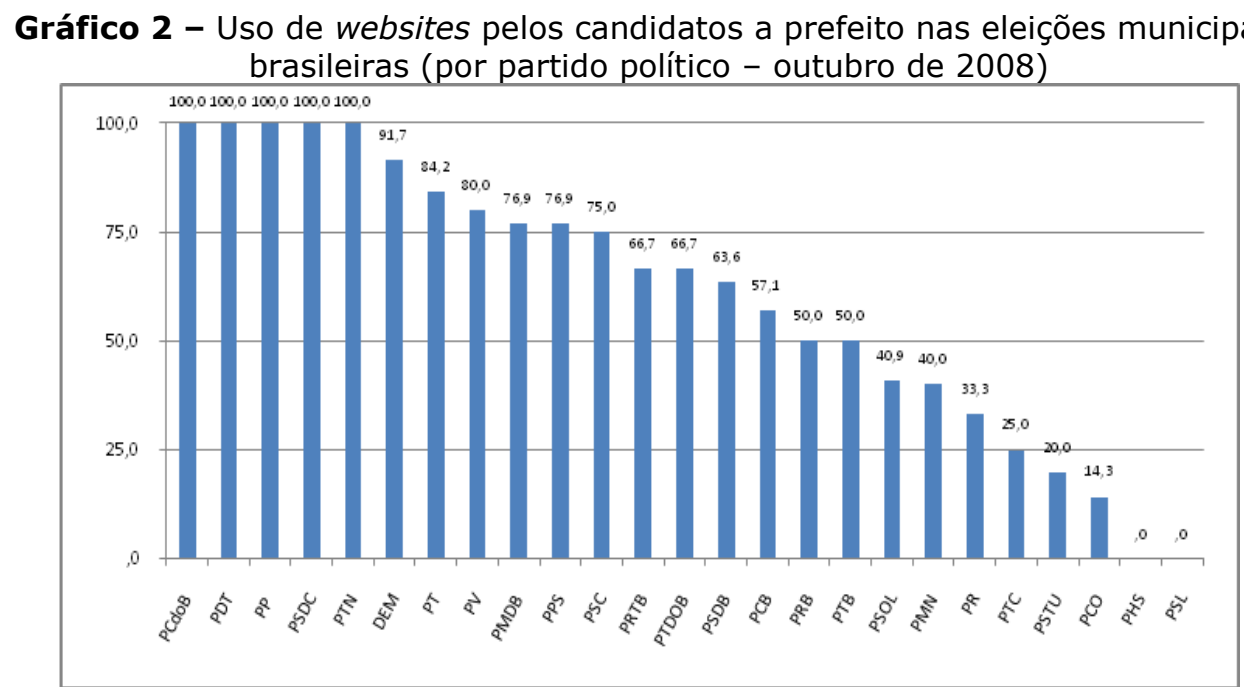

Fonte: Elaboração própria.

Pelo gráfico acima podemos verificar que não há um padrão muito definido de adesão às campanhas online pelos partidos brasileiros, ao contrário do observado em alguns outros estudos quando geralmente partidos de esquerda, de oposição ou "outsiders" ao jogo político tradicional tendem a apresentar um maior grau de uso da internet (ROMMELLE, 2003).

O padrão agregado de uso da web vis-à-vis a variável ideologia pode ser melhor visualizado pela tabela abaixo: 
Tabela 2 - Candidatos com e sem website (por partidos e linhas ideológicoprogramáticas)

\begin{tabular}{|c|c|c|c|c|c|}
\hline & \multicolumn{2}{|c|}{ Com website } & \multicolumn{2}{|c|}{ Sem website } & \multirow{2}{*}{$\begin{array}{c}\begin{array}{c}\text { Total } \\
(100 \%)\end{array} \\
\mathrm{N}\end{array}$} \\
\hline & $\mathrm{N}$ & $\%$ & $\mathrm{~N}$ & $\%$ & \\
\hline \multicolumn{6}{|c|}{ I) Partidos/agregado } \\
\hline DEM & 11 & 91,7 & 1 & 8,3 & 12 \\
\hline$\overline{\mathrm{PT}}$ & 16 & 84,2 & 3 & 15,8 & 19 \\
\hline PMDB & 10 & 76,9 & 3 & 23,1 & 13 \\
\hline PPS & 10 & 76,9 & 3 & 23,1 & 13 \\
\hline PSDB & 7 & 63,6 & 4 & 36,4 & 11 \\
\hline Ppd & 20 & 54,1 & 17 & 45,9 & 37 \\
\hline Ppe & 33 & 51,6 & 31 & 48,4 & 64 \\
\hline$\overline{\text { PTB }}$ & 3 & 50,0 & 3 & 50,0 & 6 \\
\hline \multicolumn{6}{|c|}{ II) Correntes ideológicas } \\
\hline Esquerda situação & 33 & 89,2 & 4 & 10,8 & 37 \\
\hline Direita oposição & 14 & 77,8 & 4 & 22,2 & 18 \\
\hline Centro situação & 10 & 76,9 & 3 & 23,1 & 13 \\
\hline Centro oposição & 17 & 70,8 & 7 & 29,2 & 24 \\
\hline Direita situação & 20 & 54,1 & 17 & 45,9 & 37 \\
\hline Esquerda oposição & 16 & 34,8 & 30 & 65,2 & 46 \\
\hline \multicolumn{6}{|c|}{ III) Correntes ideológicas/agregado } \\
\hline Situação & 63 & 57,3 & 24 & 36,9 & 87 \\
\hline Oposição & 47 & 42,7 & 41 & 63,1 & 88 \\
\hline Total & 110 & 62,9 & 65 & 37,1 & 175 \\
\hline
\end{tabular}

Fonte: Elaboração própria.

Os atores que mais utilizaram a Web para organizar campanhas eleitorais nas últimas eleições municipais brasileiras não foram, portanto, atores "outsiders" ao jogo político mais tradicional, mas sim os grandes partidos de direita e de esquerda que já polarizavam o debate ideológico fora do universo virtual. Assim, podemos afirmar que o uso da web foi mais intenso entre os atores com mais recursos políticos que já polarizavam o debate fora do mundo virtual (partidos de esquerda no governo e partidos de direita na oposição) ${ }^{4}$, do que por aqueles atores que poderiam se utilizar das novas tecnologias para subverter radicalmente as modalidades anteriormente vigentes de competição política e para abrir novos espaços de divulgação de propostas. Essas proposições podem ser verificadas pelo percentual inferior de pequenos partidos de direita $(54,1 \%)$ e de esquerda $(51,6 \%)$, assim como candidatos de oposição ao governo $(42,7 \%)$ que usaram website como

\footnotetext{
${ }^{4}$ Incluimos o PTB na oposição ao governo Lula devido ao progressivo afastamento do partido em relação ao governo Lula, embora alguns de seus membros participassem do gabinete do presidente. Entretanto, sublinhe-se que não efetuamos nenhum estudo mais aprofundado para verificar se os candidatos do partido mantiveram uma postura de oposição ou de situação durante a campanha eleitoral.
} 
ferramenta de campanha nas últimas eleições municipais, evidenciando que as ferramentas digitais estiveram longe de ser empregadas predominantemente por forças políticas potencialmente interessadas em subverter os padrões tradicionais de competição eleitoral.

Para caracterizar com mais precisão o padrão de uso da web pelos candidatos, cruzamos os dados de uso de websites com variáveis de perfil social (sexo, idade, grupo profissional, faixa etária), recursos políticos (patrimônio e gasto de campanha) e experiência política prévia (ocupação de cargo eletivo, exercício de cargo executivo, se está concorrendo ou não à reeleição).

Efetuados os testes e cruzamentos não foram encontradas associações significativas entre uso da web e variáveis de perfil social, sendo as mais relevantes as correlações existentes entre uso de website e recursos políticos, como pode ser ilustrado pela tabela abaixo: 
Tabela 3 - Candidatos com e sem website (por patrimônio e gasto de campanha)

\begin{tabular}{|c|c|c|c|c|c|}
\hline & \multicolumn{2}{|c|}{$\begin{array}{c}\text { Com } \\
\text { Website }\end{array}$} & \multicolumn{2}{|c|}{$\begin{array}{c}\text { Sem } \\
\text { Website }\end{array}$} & \multirow{2}{*}{$\begin{array}{c}\begin{array}{c}\text { Total } \\
(100 \%)\end{array} \\
\mathrm{N}\end{array}$} \\
\hline & $\mathrm{N}$ & $\%$ & $\mathrm{~N}$ & $\%$ & \\
\hline \multicolumn{6}{|c|}{ Patrimônio desagregado } \\
\hline Baixo-baixo: menos de 50 mil & 13 & 54,2 & 11 & 45,8 & 24 \\
\hline Baixo: de 50 mil a menos 200 mil & 20 & 55,6 & 16 & 44,4 & 36 \\
\hline $\begin{array}{l}\text { Médio-baixo: de } 200 \text { mil a menos } 500 \\
\text { mil }\end{array}$ & 26 & 74,3 & 9 & 25,7 & 35 \\
\hline $\begin{array}{l}\text { Médio-alto: de } 500 \text { mil a } 1 \text { menos } \\
\text { milhão }\end{array}$ & 23 & 69,7 & 10 & 30,3 & 33 \\
\hline Alto: de 1 milhão a menos 2 milhões & 11 & 78,6 & 3 & 21,4 & 14 \\
\hline $\begin{array}{l}\text { Alto-alto: de } 2 \text { milhões a menos } 5 \\
\text { milhões }\end{array}$ & 6 & 60,0 & 4 & 40,0 & 10 \\
\hline Super-alto=acima de 5 milhões & 7 & 87,5 & 1 & 12,5 & 8 \\
\hline Não se aplica/sem informação & 4 & 26,7 & 11 & 73,3 & 15 \\
\hline \multicolumn{6}{|c|}{ Gasto de campanha/agregado } \\
\hline Alto & 86 & 75,4 & 28 & 24,6 & 114 \\
\hline Médio & 13 & 54,2 & 11 & 45,8 & 24 \\
\hline Baixo & 10 & 29,4 & 24 & 70,6 & 34 \\
\hline Não se aplica & 1 & 33,3 & 2 & 66,7 & 3 \\
\hline \multicolumn{6}{|c|}{ Gasto de campanha/desagregado } \\
\hline Baixo-baixo: menos de 50 mil & 4 & 25,0 & 12 & 75,0 & 16 \\
\hline Baixo: de 50 mil a menos 200 mil & 6 & 33,3 & 12 & 66,7 & 18 \\
\hline $\begin{array}{l}\text { Médio-baixo: de } 200 \text { mil a menos } 500 \\
\text { mil }\end{array}$ & 7 & 58,3 & 5 & 41,7 & 12 \\
\hline $\begin{array}{l}\text { Médio-alto: de } 500 \text { mil a } 1 \text { menos } \\
\text { milhão }\end{array}$ & 6 & 50,0 & 6 & 50,0 & 12 \\
\hline Alto: de 1 milhão a menos 2 milhões & 16 & 72,7 & 6 & 27,3 & 22 \\
\hline $\begin{array}{l}\text { Alto-alto: de } 2 \text { milhões a menos } 5 \\
\text { milhões }\end{array}$ & 37 & 72,5 & 14 & 27,5 & 51 \\
\hline Super-alto=acima de 5 milhões & 33 & 80,5 & 8 & 19,5 & 41 \\
\hline Não se aplica & 1 & 33,3 & 2 & 66,7 & 3 \\
\hline Total & 110 & 62,9 & 65 & 37,1 & 175 \\
\hline
\end{tabular}

Fonte: Elaboração própria.

Como pode ser ilustrado pelos dados, há uma associação quase linear entre uso de websites pelos candidatos e magnitude dos gastos de campanhas. Assim, do total de cerca de 114 candidatos com alto patrimônio e alto gasto de campanha cerca de $75 \%$ utilizaram websites como recurso de campanha, enquanto do total de candidatos com baixos recursos menos de $30 \%$ recorreram à campanhas online.

Temos assim que o candidato mediano usuário da web nas eleições municipais de outubro de 2008 apresenta as seguintes características: situado 


\section{DOSSIÊ OPINIÃO PÚBLICA, ELEIÇÕES E PARTICIPAÇÃO POLÍTICA NAS DEMOCRACIAS CONTEMPORÂNEAS}

nas regiões sul ou sudeste do Brasil, pertencente aos grandes partidos que polarizam a opinião pública no jogo político nacional, com alto patrimônio e alto montante de gastos de campanha, e diversificado em relação a sexo, escolaridade ou categoria profissional.

Assim, aparentemente o uso da Web apenas reproduziu a "política como usual" no último pleito municipal, sem subverter significativamente os padrões de competição existentes no mundo real.

\subsection{O que fizeram os candidatos online: graus de uso da web na campanha eleitoral}

Uma vez traçado o perfil dos candidatos adeptos e não adeptos das campanhas online, resta-nos agora caracterizar o que fizeram os postulantes às prefeituras no decorrer das campanhas. Para tanto, seguimos a metodologia explicitada anteriormente, estabelecemos uma classificação dos candidatos com base no percentual de frequencia de tais variáveis e mapeamos as principais experiências de participação online encontradas nos websites dos candidatos.

No tocante aos graus de uso da web pelos diversos candidatos obtidos através da aplicação de nosso critério, eles estão resumidos no anexo a este artigo. O candidato que utilizou mais recursos da web durante a campanha eleitoral foi Geraldo Kassab (DEM/SP), seguido de Marta Suplicy (PT/SP), Cadoca (PSB/PE), Geraldo Alckimin (PSDB/SP), Edvaldo Nogueira (PCdoB/SE) e de Fernando Gabeira (PV/RJ). Fernando Gabeira, por sua vez, o candidato que mais se notabilizou na cobertura impressa pelo uso das novas mídias nas eleições de outubro de 2008, e que mais empregou recursos de mobilização e interatividade com o eleitor via novas tecnologias, obteve o sexto lugar em nossa pontuação em virtude de possuir uma frequencia inferior a outros candidatos em outras dimensões de seu website.

Cabe aqui destacar alguns aspectos dos fatores associados ao maior ou menor grau de uso da web pelos candidatos. Para tanto, optamos por dividir os cem primeiros candidatos com maior pontuação em nossa classificação em quatro quartis e, assim como o fizemos anteriormente em relação ao uso de websites, cruzamos os dados de graus de uso da web por variáveis de localização geográfica, pertencimento programático-partidário, perfil social, recursos políticos e trajetória política prévia. Os dados mais significativos estão sintetizados nas tabelas a seguir. 
DOSSIÊ OPINIÃO PÚBLICA, ELEIÇÕES E PARTICIPAÇÃO POLÍTICA NAS DEMOCRACIAS CONTEMPORÂNEAS

Tabela 4 - Intensidade do uso da $W e b \times$ região

\begin{tabular}{l|c|c|c|c|c|c|c|c|c|c}
\hline & \multicolumn{2}{|c|}{ Alto } & \multicolumn{2}{|c|}{ Médio alto } & \multicolumn{2}{c|}{ Médio baixo } & \multicolumn{2}{c|}{ Baixo } & Total & \\
\hline & $\mathrm{N}$ & $\%$ & $\mathrm{~N}$ & $\%$ & $\mathrm{~N}$ & $\%$ & $\mathrm{~N}$ & $\%$ & $\mathrm{~N}$ & $\%$ \\
\hline Centro-oeste & 0 & 0,0 & 0 & 0,0 & 3 & 60,0 & 2 & 40,0 & 5 & 100 \\
\hline Nordeste & 8 & 20,0 & 11 & 27,5 & 7 & 17,5 & 14 & 35,0 & 40 & 100 \\
\hline Norte & 1 & 6,3 & 4 & 25,0 & 4 & 25,0 & 7 & 43,8 & 16 & 100 \\
\hline Sudeste & 9 & 31,0 & 4 & 13,8 & 9 & 31,0 & 7 & 24,1 & 29 & 100 \\
\hline Sul & 9 & 45,0 & 7 & 35,0 & 2 & 10,0 & 2 & 10,0 & 20 & 100 \\
\hline Total & $\mathbf{2 7}$ & $\mathbf{2 4 , 5}$ & $\mathbf{2 6}$ & $\mathbf{2 3 , 6}$ & $\mathbf{2 5}$ & $\mathbf{2 2 , 7}$ & $\mathbf{3 2}$ & $\mathbf{2 9 , 1}$ & $\mathbf{1 1 0}$ & $\mathbf{1 0 0}$ \\
\hline \multicolumn{8}{|c|}{ Fonte: Elaboração própria. }
\end{tabular}

No caso da variação por região, podemos verificar uma significativa variação entre as várias regiões geoeconômicas do país, destacando-se a esse respeito a região Sul. Pelos dados da tabela podemos observar que os candidatos localizados na região sul do país não apenas usaram mais websites, como o usaram de forma mais intensa do que outras regiões do país. Assim, enquanto $80 \%$ dos candidatos localizados nessa região obtiveram pontuação alta e média alta de uso da $W e b$, as demais regiões obtiveram percentuais bastante inferiores. Entretanto, a associação regional não é tão estreita como o uso puro e simples de website observado no item anterior, devido à baixa intensidade de uso de recursos mais sofisticados da Web em estados com IDH inferior, tais como Vitória (ES) e Belo Horizonte (MG), cujos candidatos revelaram baixa qualidade de presença online em comparação com São Paulo e Rio por exemplo.

No tocante às demais dimensões, observamos uma intensa associação entre intensidade de uso dos recursos da web e filiação partidária, posse de recursos políticos e experiência política prévia, enquanto inexistiu tal associação no tocante a variáveis relacionadas à idade (candidatos de todas as faixas etárias empregaram os recursos da web com grau semelhante), grau de instrução e categoria profissional. À diferença do item anterior, no entanto, a variável sexo influiu significativamente no tipo de uso de website, com as candidatas mulheres apresentando uma chance $20 \%$ superior do que os homens de utilizarem websites com graus alto e médio alta de intensidade de uso da web. 
DOSSIÊ OPINIÃO PÚBLICA, ELEIÇÕES E PARTICIPAÇÃO POLÍTICA NAS DEMOCRACIAS CONTEMPORÂNEAS

Tabela 5 - Intensidade do uso da Web X partido/sexo/gasto de campanha/resultado eleitoral

\begin{tabular}{|c|c|c|c|c|c|c|c|c|c|}
\hline & \multicolumn{2}{|c|}{ Alto } & \multicolumn{2}{|c|}{ Médio alto } & \multicolumn{2}{|c|}{ Médio baixo } & \multicolumn{2}{|c|}{ Baixo } & \multirow{2}{*}{$\frac{\text { Total }}{\mathrm{N}}$} \\
\hline & $\mathrm{N}$ & $\%$ & $\mathrm{~N}$ & $\%$ & $\mathrm{~N}$ & $\%$ & $\mathrm{~N}$ & $\%$ & \\
\hline \multicolumn{10}{|c|}{ PARTIDOS/AGREGADO } \\
\hline DEM & 4 & 36,4 & 4 & 36,4 & 2 & 18,2 & 1 & 9,1 & 11 \\
\hline PMDB & 2 & 20,0 & 2 & 20,0 & 4 & 40,0 & 2 & 20,0 & 10 \\
\hline PPD & 1 & 5,0 & 4 & 20,0 & 4 & 20,0 & 11 & 55,0 & 20 \\
\hline PPE & 8 & 24,2 & 7 & 21,2 & 8 & 24,2 & 10 & 30,3 & 33 \\
\hline PPS & 2 & 20,0 & 3 & 30,0 & 2 & 20,0 & 3 & 30,0 & 10 \\
\hline PSDB & 2 & 28,6 & 2 & 28,6 & 0 &, 0 & 3 & 42,9 & 7 \\
\hline PT & 7 & 43,8 & 4 & 25,0 & 4 & 25,0 & 1 & 6,3 & 16 \\
\hline PTB & 1 & 33,3 & 0 & ,0 & 1 & 33,3 & 1 & 33,3 & 3 \\
\hline \multicolumn{10}{|c|}{ SEXO } \\
\hline Feminino & 9 & 47,4 & 4 & 21,1 & 3 & 15,8 & 3 & 15,8 & 19 \\
\hline Masculino & 18 & 19,8 & 22 & 24,2 & 22 & 24,2 & 29 & 31,9 & 91 \\
\hline \multicolumn{10}{|c|}{ GASTO DE CAMPANHA/DESAGREGADO } \\
\hline $\begin{array}{c}\text { Baixo-baixo: menos } \\
\text { de } 50 \text { mil }\end{array}$ & 2 & 15,40 & 1 & 7,70 & 3 & 23,10 & 7 & 53,80 & 13 \\
\hline $\begin{array}{c}\text { Baixo: de } 50 \text { mil a } \\
\text { menos } 200 \text { mil }\end{array}$ & 3 & 15,00 & 6 & 30,00 & 4 & 20,00 & 7 & 35,00 & 20 \\
\hline $\begin{array}{l}\text { Médio-baixo: de } 200 \\
\text { mil a menos } 500 \text { mil }\end{array}$ & 6 & 23,10 & 5 & 19,20 & 10 & 38,50 & 5 & 19,20 & 26 \\
\hline $\begin{array}{l}\text { Médio-alto: de } 500 \text { mil } \\
\text { a } 1 \text { menos milhão }\end{array}$ & 7 & 30,40 & 5 & 21,70 & 3 & 13,00 & 8 & 34,80 & 23 \\
\hline $\begin{array}{l}\text { Alto: de } 1 \text { milhão a } \\
\text { menos } 2 \text { milhões }\end{array}$ & 3 & 27,30 & 5 & 45,50 & 2 & 18,20 & 1 & 9,10 & 11 \\
\hline $\begin{array}{l}\text { Alto-alto: de } 2 \text { milhões } \\
\text { a menos } 5 \text { milhões }\end{array}$ & 1 & 16,70 & 1 & 16,70 & 2 & 33,30 & 2 & 33,30 & 6 \\
\hline $\begin{array}{c}\text { Super-alto = acima de } \\
5 \text { milhões }\end{array}$ & 4 & 57,10 & 2 & 28,60 & 1 & 14,30 & 0 & 0,00 & 7 \\
\hline Não se aplica & 1 & 25,00 & 1 & 25,00 & 0 & 0,00 & 2 & 50,00 & 4 \\
\hline \multicolumn{10}{|c|}{ RESULTADO } \\
\hline Perdedor & 18 & 20,0 & 23 & 25,6 & 20 & 22,2 & 29 & 32,2 & 90 \\
\hline Vencedor & 9 & 45,0 & 3 & 15,0 & 5 & 25,0 & 3 & 15,0 & 20 \\
\hline TOTAL & 27 & 24,50 & 26 & 23,60 & 25 & 22,70 & 32 & 29,10 & 110 \\
\hline
\end{tabular}

Resumindo as características do grau de uso dos recursos da web pelos candidatos, podemos afirmar que o candidato típico que investiu mais em recursos de campanha online situava-se na região sul do país, era de um grande partido de esquerda ou de direita que polarizava o debate político em nível nacional num gradiente governo $X$ oposição, era do sexo feminino, gastou um alto montante de recursos na campanha eleitoral e teve maior probabilidade de ser bem-sucedido eleitoralmente. 


\subsection{Frequencia dos mecanismos de interação e participação}

Por fim, resta-nos efetuar uma análise mais detida de algumas práticas de participação política e de maior manifestação das falas e das demandas do cidadão-internauta nos websites dos candidatos.

Para mapear a frequencia dos mecanismos interação e oportunidades de participação política nos websites dos candidatos, recorreremos ao modelo dos fluxos de interatividade de Ferber e o grau de presença de manifestações dos cidadãos em cada um desses espaços virtuais. Agrupamos estas últimas ocorrências em quatro quartis, de acordo com a quantidade de manifestações dos cidadãos-internautas observada, ou do grau de retorno dos gestores dos sites aos experimentos feitos pela equipe de pesquisa (baixa, média e alta intensidade, respectivamente $)^{5}$. Os dados encontram-se resumidos na tabela abaixo:

Tabela 6 - Mecanismos de participação política nos websites dos candidatos às prefeituras das capitais no pleito de outubro de 2008 no Brasil

\begin{tabular}{|c|c|c|c|c|c|c|c|}
\hline & \multirow{2}{*}{$\begin{array}{c}\text { Mecanismos de } \\
\text { Participação e } \\
\text { Interação }\end{array}$} & \multicolumn{2}{|c|}{ Sim } & \multicolumn{2}{|c|}{ Não } & \multirow{2}{*}{$\begin{array}{l}\text { Tipo de } \\
\text { interação }\end{array}$} & \multirow{2}{*}{$\begin{array}{c}\text { Grau de } \\
\text { participação } \\
\text { observado }\end{array}$} \\
\hline & & $\mathbf{N}$ & $\%$ & $\mathbf{N}$ & $\%$ & & \\
\hline 1 & $\begin{array}{l}\text { Formulário para contato } \\
\text { sem e-mail/fale conosco }\end{array}$ & 73 & 66,4 & 37 & 33,6 & Feedback & $\begin{array}{l}\text { Baixa } \\
\text { intensidade }\end{array}$ \\
\hline 2 & $\begin{array}{l}\text { E-mail do candidato ou } \\
\text { do comitê }\end{array}$ & 43 & 39,1 & 67 & 60,9 & Feedback & $\begin{array}{l}\text { Baixa } \\
\text { intensidade }\end{array}$ \\
\hline 3 & $\begin{array}{l}\text { Link para Blogs na } \\
\text { página inicial }\end{array}$ & 40 & 36,4 & 70 & 63,6 & Monólogo & $\begin{array}{l}\text { Média } \\
\text { intensidade }\end{array}$ \\
\hline 4 & $\begin{array}{l}\text { Ajudar divulgando pela } \\
\text { internet }\end{array}$ & 39 & 35,8 & 70 & 64,2 & Monólogo & \begin{tabular}{|l} 
Baixa \\
intensidade
\end{tabular} \\
\hline 5 & Blog atualizado? & 32 & 29,1 & 78 & 70,9 & \begin{tabular}{|l} 
Diálogo \\
responsivo
\end{tabular} & Alta intensidade \\
\hline 6 & $\begin{array}{l}\text { Enquete sobre temas } \\
\text { polêmicos na página } \\
\text { inicial }\end{array}$ & 31 & 28,2 & 79 & 71,8 & $\begin{array}{l}\text { Diálogo } \\
\text { responsivo }\end{array}$ & $\begin{array}{l}\text { Baixa } \\
\text { intensidade }\end{array}$ \\
\hline 7 & $\begin{array}{l}\text { Há indício do uso de } \\
\text { mídias sociais }\end{array}$ & 26 & 25,0 & 78 & 75,0 & $\begin{array}{l}\text { Discurso } \\
\text { público }\end{array}$ & $\begin{array}{l}\text { Baixa } \\
\text { intensidade }\end{array}$ \\
\hline 8 & Resultados da enquete & 27 & 24,5 & 83 & 75,5 & $\begin{array}{l}\text { Diálogo } \\
\text { responsivo }\end{array}$ & \begin{tabular}{|l|} 
Baixa \\
intensidade
\end{tabular} \\
\hline 9 & Canal no youtube? & 24 & 23,1 & 80 & 76,9 & \begin{tabular}{|l} 
Discurso \\
Público \\
\end{tabular} & $\begin{array}{l}\text { Baixa } \\
\text { intensidade }\end{array}$ \\
\hline 10 & $\begin{array}{l}\text { Acervo de comentários } \\
\text { dos internautas }\end{array}$ & 22 & 20,0 & 88 & 80,0 & $\begin{array}{l}\text { Resposta } \\
\text { controlada }\end{array}$ & $\begin{array}{l}\text { Média } \\
\text { intensidade }\end{array}$ \\
\hline
\end{tabular}

\footnotetext{
${ }^{5}$ Para uma exemplificação da forma como aplicamos tal metodologia, cf. os websites com alto grau de intensidade de participação vinculados em Braga, França e Nicolas (2009).
} 
DOSSIÊ OPINIÃO PÚBLICA, ELEIÇÕES E PARTICIPAÇÃO POLÍTICA NAS DEMOCRACIAS CONTEMPORÂNEAS

\begin{tabular}{|c|c|c|c|c|c|c|c|}
\hline 11 & $\begin{array}{l}\text { Sugestões para } \\
\text { propostas de governo }\end{array}$ & 20 & 18,2 & 90 & 81,8 & $\begin{array}{l}\text { Resposta } \\
\text { controlada }\end{array}$ & $\begin{array}{l}\text { Baixa } \\
\text { intensidade }\end{array}$ \\
\hline 12 & $\begin{array}{l}\text { Possibilidade de } \\
\text { comentar notícias } \\
\text { postadas }\end{array}$ & 17 & 15,5 & 93 & 84,5 & $\begin{array}{l}\text { Resposta } \\
\text { controlada }\end{array}$ & $\begin{array}{l}\text { Média } \\
\text { intensidade }\end{array}$ \\
\hline 13 & $\begin{array}{l}\text { Vídeos com depoimentos } \\
\text { dos eleitores }\end{array}$ & 15 & 14,7 & 87 & 85,3 & $\begin{array}{l}\text { Diálogo } \\
\text { responsivo }\end{array}$ & Alta intensidade \\
\hline 14 & $\begin{array}{l}\text { Link para youtube na pag } \\
\text { inicial }\end{array}$ & 15 & 14,4 & 89 & 85,6 & Monólogo & \begin{tabular}{|l} 
Baixa \\
intensidade
\end{tabular} \\
\hline 15 & Mural de mensagens & 15 & 13,6 & 95 & 86,4 & $\begin{array}{l}\text { Resposta } \\
\text { controlada }\end{array}$ & Alta intensidade \\
\hline 16 & $\begin{array}{l}\text { Link para comunidade } \\
\text { orkut na página inicial }\end{array}$ & 14 & 12,7 & 96 & 87,3 & $\begin{array}{l}\text { Debate } \\
\text { Público }\end{array}$ & $\begin{array}{l}\text { Média } \\
\text { intensidade }\end{array}$ \\
\hline 17 & Orkut & 12 & 11,5 & 92 & 88,5 & $\begin{array}{l}\text { Debate } \\
\text { Público }\end{array}$ & $\begin{array}{l}\text { Baixa } \\
\text { intensidade }\end{array}$ \\
\hline 18 & $\begin{array}{l}\text { Espaço para postagem } \\
\text { nos blogs? }\end{array}$ & 10 & 9,1 & 100 & 90,9 & $\begin{array}{l}\text { Diálogo } \\
\text { responsivo }\end{array}$ & Alta intensidade \\
\hline 19 & $\begin{array}{l}\text { Salas de Bate- } \\
\text { Papo/chats com } \\
\text { candidato }\end{array}$ & 7 & 5,5 & 103 & 93,6 & $\begin{array}{l}\text { Resposta } \\
\text { controlada }\end{array}$ & $\begin{array}{l}\text { Baixa } \\
\text { intensidade }\end{array}$ \\
\hline 20 & $\begin{array}{l}\text { Link específico para } \\
\text { denúncias/reclamações }\end{array}$ & 5 & 4,5 & 105 & 95,5 & \begin{tabular}{|l} 
Diálogo \\
responsivo
\end{tabular} & $\begin{array}{l}\text { Baixa } \\
\text { intensidade }\end{array}$ \\
\hline 21 & $\begin{array}{l}\text { Acervo dos chats } \\
\text { realizados }\end{array}$ & 4 & 3,6 & 106 & 96,4 & $\begin{array}{l}\text { Resposta } \\
\text { controlada }\end{array}$ & $\begin{array}{l}\text { Baixa } \\
\text { intensidade }\end{array}$ \\
\hline 22 & $\begin{array}{l}\text { Fórum/Discussão sobre } \\
\text { temas específicos }\end{array}$ & 4 & 3,6 & 106 & 96,4 & $\begin{array}{l}\text { Resposta } \\
\text { controlada }\end{array}$ & $\begin{array}{l}\text { Baixa } \\
\text { intensidade }\end{array}$ \\
\hline 23 & Twitter & 3 & 2,9 & 101 & 97,1 & $\begin{array}{l}\text { Debate } \\
\text { Público }\end{array}$ & $\begin{array}{l}\text { Baixa } \\
\text { intensidade }\end{array}$ \\
\hline 24 & $\begin{array}{l}\text { Acervo dos fóruns } \\
\text { realizados }\end{array}$ & 3 & 2,7 & 107 & 97,3 & $\begin{array}{l}\text { Resposta } \\
\text { controlada }\end{array}$ & $\begin{array}{l}\text { Baixa } \\
\text { intensidade }\end{array}$ \\
\hline 25 & Delicious & 2 & 1,9 & 102 & 98,1 & $\begin{array}{l}\text { Debate } \\
\text { Público }\end{array}$ & $\begin{array}{l}\text { Baixa } \\
\text { intensidade }\end{array}$ \\
\hline 26 & Facebook & 1 & 1,0 & 109 & 99,0 & $\begin{array}{l}\text { Debate } \\
\text { Público }\end{array}$ & $\begin{array}{l}\text { Baixa } \\
\text { intensidade }\end{array}$ \\
\hline 27 & Myspace & 1 & 1,0 & 109 & 99,0 & $\begin{array}{l}\text { Debate } \\
\text { Público }\end{array}$ & $\begin{array}{l}\text { Baixa } \\
\text { intensidade }\end{array}$ \\
\hline 28 & Sonico & 1 & 1,0 & 109 & 99,0 & $\begin{array}{l}\text { Debate } \\
\text { Público }\end{array}$ & $\begin{array}{l}\text { Baixa } \\
\text { intensidade }\end{array}$ \\
\hline
\end{tabular}

Fonte: Elaboração própria.

A tabela acima nos informa a intensidade dos mecanismos de interação e oportunidades de participação política encontrados nos websites dos 110 candidatos que utilizaram este recurso nas campanhas eleitorais para as prefeituras das capitais brasileiras de outubro de 2008, o tipo de interação possibilitada segundo o modelo de Ferber, Foltz e Puglise (2007) e o grau de 
efetividade das experiências de interação observados durante nossa pesquisa. Como podemos observar pelos dados acima, mídias sociais como Facebook, Twitter, e postagem de vídeos no Youtube foram escassamente utilizadas, inclusive devido às interdições à campanha pela internet vigentes na legislação eleitoral brasileira. Por outro lado, predominaram mecanismos tradicionais e top down de interação, tais como newsletter e e-mails, sem tentativas de criar espaços de deliberação e/ou participação políticos mais abrangentes. As ferramentas virtuais para as quais foram coletadas mais evidências de interação foram links para blogs na página inicial (40 candidatos apresentaram links para blogs, verificando-se uma intensidade razoável de acessos e comentários aos blogs durante as campanhas eleitorais), blogs atualizados (dentre os 32 candidatos que disponibilizaram blogs atualizados de campanha, foi observada uma alta intensidade de participação, com os cidadãos acessando os blogs e efetuando postagens em boa parte deles), assim como vídeos com depoimentos dos eleitores, que tiveram uma boa aceitação como recurso de campanha virtual nas últimas eleições municipais. Por outro lado, recursos tais como respostas a e-mails e formulários disponibilizados pelos candidatos, mídias sociais, enquetes, sugestões para propostas de governo, salas de bate-papo e outros, foram escassamente utilizados ou, quando utilizados, possibilitaram poucas possibilidades de interação com o eleitor, permanecendo como ferramentas disponibilizadas pelos candidatos, mas pouco utilizadas pelos eleitores.

\section{Conclusões}

Retomando os questionamentos que nortearam nosso trabalho de uma maneira geral os mecanismos de participação e interação além de pouco frequentes nos websites dos candidatos, foram utilizados com reduzida intensidade, a exceção de alguns exemplos enumerados no ranking que segue anexo a este texto, destacando-se os casos do candidato a prefeito de São Paulo, Gilberto Kassab (DEM) e do candidato a prefeito do Rio de Janeiro, Fernando Gabeira (PV). Também com base nos dados analisados podemos afirmar que os candidatos não utilizaram de maneira substantiva os mecanismos da Web 2.0. em seus sítios especialmente devido às restrições ou ambiguidades da legislação eleitoral vigente no Brasil. Este termo se popularizou durante a campanha do democrata Barak Obama nos Estados Unidos (2008) e se relaciona com campanhas na Net que são participativas, na qual existe uma utilização intensiva de redes sociais, blogs, Youtube, entre outras ferramentas que disponibilizam mais interação e participação dos internautas com possibilidades destes postarem suas próprias mensagens com maior facilidade (GOMES, 2009).

Muitos analistas, sobre os impactos da internet na política, ao detectarem a timidez das experiências participacionistas mais avançadas e um alto índice de "campanha negativa" via Web nas eleições, manifestam uma 


\section{DOSSIÊ OPINIÃO PÚBLICA, ELEIÇÕES E PARTICIPAÇÃO POLÍTICA NAS DEMOCRACIAS CONTEMPORÂNEAS}

perspectiva "pessimista" em relação ao futuro emprego da internet nas campanhas eleitorais brasileiras, ao verificarem a ausência de mecanismos de mobilização e deliberação políticas mais sofisticados que poderiam ser estimuladas por intermédio das novas tecnologias. Esta não é, esclareça-se por fim, a perspectiva deste texto. Consideramos que, embora utilizadas num estágio ainda embrionário pelos candidatos nas eleições brasileiras até aqui, as ferramentas disponibilizadas pelas novas tecnologias aos candidatos indicam potencialidades e tendências futuras que muito provavelmente devem se concretizar nos próximos pleitos eleitorais, desencadeando um longo processo de aprendizado de tais mídias pelos diversos atores sociais, e provavelmente causando (novas) surpresas aos observadores mais desavisados.

Sérgio Braga é Professor de Ciência Política do Departamento de Ciências Sociais da UFPR e coordenador do grupo de trabalho "Ciberpolítica, ciberativismo e cibercultura" da Associação Nacional de Pesquisadores de PósGraduação em Ciências Sociais (Anpocs).

E-mail: ssbraga@uol.com.br

Maria Alejandra Nicolás é doutoranda em Sociologia (UFPR), Mestre em Sociologia (UFPR), Especialista em Gestão de Programas, Projetos e Políticas Sociais (PUC-PR) e Graduada em Ciência Política pela Universidad de Buenos Aires.

E-mail: alejandranicolas@gmail.com

Andressa Silvério Terra França é doutoranda em Sociologia (UFPR) e Mestre em Sociologia (UFPR).

E-mail: andressastf@gmail.com

\section{Referências}

AGGIO, Camilo. Campanhas online: o percurso de formação das questões, problemas e configurações a partir da literatura produzida entre 1992 e 2009. Opinião Pública, Campinas, v. 16, n. 2, p. 426-445, nov. 2010.

ALDÉ, Alessandra; BORGES, Juliano. Internet, imprensa e as eleições de 2002: pautando notícias em tempo real. Revista Logos, Rio de Janeiro, v. 21, p. 107-132, 10 sem. 2004.

BIMBER, Bruce; DAVID, Richard. Campaigning on-line: the Internet in U. S. elections. Oxford: Oxford University Press, 2003.

BRAGA, Sérgio. O papel das TICs na institucionalização das democracias; um 
estudo sobre a informatização dos órgãos legislativos na América do Sul com destaque para o Brasil. Brasília: Plenarium/CEDI, 2007. Disponível em: <http://www2.camara.gov.br/internet/eve/realizados/portal_seminario2007/ material.html>. Acesso em: 25 abr. 2007.

. Podemos ter um(a) nov@ Obama? Perspectivas do uso da Web no próximo pleito eleitoral brasileiro. Em Debate, Belo Horizonte, v. 2, p. 10-18, abr. 2010.

BRAGA, Sérgio; CRUZ, Letícia Carina; FRANÇA, Andressa Silvério Terra. Como os políticos brasileiros estão usando a internet para se comunicar e interagir com o eleitor? Um estudo sobre o uso da internet pelos candidatos às eleições de outubro de 2006 na região Sul do Brasil. Política \& Sociedade, Florianópolis, v. 6, n. 10, p. 219-242, abr. 2007.

BRAGA, Sérgio; NICOLÁS, Alejandra. Prosopografia a partir da web: avaliando e mensurando as fontes para o estudo das elites parlamentares brasileiras na internet. Revista Sociologia e Política, Curitiba, v. 16, n. 30, p. 107-130, jun. 2008.

BRAGA, Sérgio; NICOLÁS, Alejandra; FRANÇA, Andressa Silvério Terra. Mecanismos de participação nos websites dos candidatos a prefeito nas eleições de 2008 no Brasil. In: ENCONTRO DA ABCP, 7., 2010, Recife/PE. Anais do VII Encontro da ABCP, 2010.

BRANDÃO JR., Francisco de Assis F. Palanques virtuais: a campanha presidencial pela internet nas eleições de 2006. 2008. 224 f. Dissertação (Mestrado em Ciência Política) - Instituto de Ciência Política, UnB/Universidade de Brasília, [2008].

BRANDÃO, Francisco de Assis; BATISTA, Carlos Marcos. Palanques virtuais: o uso de sites, e-mails e comunidades eletrônicas nas eleições de 2006. In: ENCONTRO DA ABCP, 6., 2007, Unicamp. Anais do VI Encontro da ABCP, 2007.

CHADWIK, Andrew; HOWARD, Philip. A Handbook of Internet and Politics. London: Routledge, 2008.

CHAIA, Vera. Internet e eleições: as comunidades políticas no orkut nas eleições de 2006. Logos Comunicação e Universidade, ano 14, v. 27, p. 127140, $2^{\circ}$ sem. 2007.

COHEN, Diana. The Web of Candidates and Parties: Internet Functionality in the 2004 Election. In: ANNUAL MEETING OF THE MIDWEST POLITICAL 


\section{DOSSIÊ OPINIÃO PÚBLICA, ELEIÇÕES E PARTICIPAÇÃO POLÍTICA NAS DEMOCRACIAS CONTEMPORÂNEAS}

SCIENCE ASSOCIATION, 64., 2006, Chicago. Disponível em: <http://www.allacademic.com/meta/p137023_index.html>. Acesso em: 21 dez. 2011.

CORNFIELD, Michael. Politics moves online: campaigning and the Internet. New York: Century Foundation Press, 2004.

COUTINHO, Marcelo; SAFATLE, Vladimir. A internet e as eleições municipais em 2008: o uso dos sítios eletrônicos de comunidades na eleição paulistana. Revista de Sociologia e Política, Curitiba, v. 17, n. 34, p.115-128, out. 2009.

DAVIS, Richard. The Web of Politics: The Internet's Impact on the American Political System. Oxford: Oxford University Press, 1999.

FERBER, Paul; FOLTZ, Franz; PUGLIESE, Rudy. Cyberdemocracy and online politics: a new model of interactivity. Bulletin of Science, Technology \& Society, v. 27, n. 5, p. 391-400, oct. 2007.

FERNANDEZ, Rogério Garcia. Campanhas eleitorais na internet. 2005. $136 \mathrm{f}$. Dissertação (Mestrado em Ciência Política) - IFCH, UNICAMP, [2005].

GAINOUS, Jason, WAGNER, Kevin. Electronic Grassroots: Does Online Campaigning Work?. The Journal of Legislative Studies, London, v. 15, n. 4, p. 502-520, dec. 2009.

GIBSON, Rachel; WARD, Stephen. A proposed methodology for studding the function and effectiveness of party and candidate web sites. Social Science Computer Review, v. 18, n. 3, p. 301-319, fall 2000.

GOMES, Wilson et al. Politics 2.0: a campanha online de Barak Obama em 2008. Revista de Sociologia e Política, Curitiba, v. 17, n. 34, p. 29-43, out. 2009.

GOMES, Wilson; AGGIO, Camilo. Campanhas Online: O percurso de formação das questões, problemas e configurações a partir da literatura produzida entre 1992 e 2009. In: SEMINÁRIO NACIONAL SOCIOLOGIA E POLÍTICA, 1., 2009, Curitiba. Anais do I Seminário Nacional Sociologia \& Política, UFPR, 2009, v. I.

IASULAITIS, Sylvia. Internet e propaganda política no Brasil: limites e possibilidades. Estudos de Sociologia, Araraquara, v. 12, n. 23, p. 153-172, 10 sem. 2007.

IRELAND, Emilienne; NASH, Phil Tajitsu. Winning campaigns on-line: strategies for candidates and causes. 2. ed. Bethesda: Science Writers Pr., 
2001.

LILLEKER, Darren G.; JACKSON, Nigel A. Interacting and Representing: can Web 2.0 enhance the roles of an MP? In: ECPR JOINT SESSIONS, Lisbon 2009. Available:

<http://internet-politics.cies.iscte.pt/IMG/pdf/ECPR2009Lilleker-

Jackson.pdf>. Access: 21 dec. 2011.

MARGOLIS, Michael; RESNICK, David. Politics as usual: The cyberspace "Revolution". Thousand Oaks, CA: Sage, 2000.

NORRIS, Pippa. Digital Divide: Civic Engagement, Information Poverty, and the Internet Worldwide. Cambridge: Cambridge University Press, 2001.

PARKIN, Michael. Congressional Campaigns in Cyberspace and the Effect of Presentation Technology on Website Visitors. In: ANNUAL MEETING OF THE MIDWEST POLITICAL SCIENCE ASSOCIATION, 15., 2007, Chicago, Illinois. Available:

<http://citation.allacademic.com/meta/p_mla_apa_research_citation/1/9/9/0 /9/pages199095/p199095-1.php>. Access: 21 dec. 2011.

ROMMELE, Andrea. Political Parties, Party Comunnication and New Information and Communication Technologies. Party Politics, London, v. 9, n. 1, p. 7-20, jan. 2003.

TRIPPI, Joe. The revolution will not be televised: democracy, the Internet, and the overthrow of everything. New York: Regan Books, 2004. 


\section{DOSSIÊ OPINIÃO PÚBLICA, ELEIÇÕES E PARTICIPAÇÃO POLÍTICA NAS DEMOCRACIAS CONTEMPORÂNEAS}

Anexo - Intensidade de uso dos recursos da Web pelos candidatos às prefeituras municipais de 2008

\begin{tabular}{|c|c|c|c|c|c|}
\hline $\mathbf{N}$ & Nome eleitoral & Website & Partido & Capital & Média \\
\hline 1 & Gilberto Kassab & http://www.kassab25.com.br/ & DEM & São Paulo & 80,0 \\
\hline 2 & Marta & http://www.marta13.can.br/ & PT & São Paulo & 68,7 \\
\hline 3 & Gabeira & www.gabeira.com.br/ & PV & Rio de Janeiro & 66,7 \\
\hline 4 & Cadoca & http://www.cadoca.can.br/ & PSC & Recife & 66,7 \\
\hline 5 & Geraldo Alckmin & http://www.geraldo45.com.br/ & PSDB & São Paulo & 64,0 \\
\hline 6 & Edvaldo Nogueira & www.edvaldo65.can.br & PCdoB & Aracaju & 63,3 \\
\hline 7 & Manuela & http://www.manuela65.com.br/novo/ & PCdoB & Porto Alegre & 60,7 \\
\hline 8 & Maria do Rosario & http://www.mariadorosarioprefeita.com.br/ & PT & Porto Alegre & 60,7 \\
\hline 9 & Fabio Camargo & http://www.fabiocamargo14.can.br/ & PTB & Curitiba & 60,7 \\
\hline 10 & Nildao & http://www.nildao13.can.br/ & $\mathrm{PT}$ & Florianópolis & 57,3 \\
\hline 11 & Bruno Meirinho & http://www.brunomeirinho50.can.br/ & PSOL & Curitiba & 56,0 \\
\hline 12 & Gleisi & http://www.gleisi13.can.br/ & PT & Curitiba & 55,3 \\
\hline 13 & Joao da Costa & http://www.joaodacosta13.can.br/home/home.php & PT & Recife & 54,0 \\
\hline 14 & Mendonça & http://mendonca25.can.br/ & DEM & Recife & 53,3 \\
\hline 15 & Chico Alencar & www.chico50.com.br/ & PSOL & Rio de Janeiro & 53,3 \\
\hline 16 & Pinheiro & http://pinheiro13.can.br & PT & Salvador & 51,3 \\
\hline 17 & Marcio Lacerda & http://www.marciolacerda40.can.br/ & PPS & Belo Horizonte & 50,7 \\
\hline 18 & Angela Albino & http://www.angela65.com.br/ & PCdoB & Florianópolis & 49,3 \\
\hline 19 & Luzianne Lins & http://www.luizianne13.can.br & PT & Fortaleza & 49,3 \\
\hline 20 & Eduardo Paes & www.eduardopaes15.can.br/ & PMDB & Rio de Janeiro & 49,3 \\
\hline 21 & Jose Fogaça & http://www.fogaca15.com.br & PMDB & Porto Alegre & 48,7 \\
\hline 22 & Valeria & http://www.valeria25.can.br & DEM & Belém & 48,7 \\
\hline 23 & Beto Richa & http://www.betoricha45.can.br/ & PSDB & Curitiba & 48,0 \\
\hline 24 & Moroni & http://www.moroni25.com.br & DEM & Fortaleza & 48,0 \\
\hline 25 & Ivan Valente & http://www.ivanvalente50.com.br/campanha/ & PSOL & São Paulo & 46,7 \\
\hline 26 & Micarla de Sousa & http://www.micarla43.can.br & $\mathrm{PV}$ & Natal & 46,0 \\
\hline 27 & Soninha & http://www.soninha23.can.br/ & PPS & São Paulo & 45,3 \\
\hline 28 & Alessandro Molon & www.molon.com.br/ & PT & Rio de Janeiro & 45,3 \\
\hline 29 & Mendonça Prado & www.mendocaprado.can.br & DEM & Aracaju & 44,7 \\
\hline 30 & ACM Neto & http://www.acmneto25.com.br/ & DEM & Salvador & 44,0 \\
\hline 31 & Clodomir Paz & http://www.clodomirpaz12.can.br & PDT & São Luiz & 43,3 \\
\hline 32 & Cesar Souza Junior & http://www.cesarsouzajunior25.com.br/ & DEM & Florianópolis & 43,3 \\
\hline 33 & Ricardo Gomyde & http://www.gomyde65.can.br/ & PCdoB & Curitiba & 42,0 \\
\hline 34 & Esperidiao Amin & http://www.amin11.com.br/ & $\mathrm{PP}$ & Florianópolis & 41,3 \\
\hline 35 & Solange & http://www.solangeamaral.com.br/ & DEM & Rio de Janeiro & 41,3 \\
\hline 36 & Arnaldo Jordy & http://www.jordy23.com.br & PPS & Belém & 41,3 \\
\hline 37 & Jô Moraes & http://www.jo65.com.br/bhevoce/ & PCdoB & Belo Horizonte & 40,7 \\
\hline 38 & Maluf & http://www.paulomaluf11.can.br/ & $\mathrm{PP}$ & São Paulo & 40,0 \\
\hline 39 & Mauricio Furtado & http://www.mauriciofurtado43.can.br & $\mathrm{PV}$ & Curitiba & 39,3 \\
\hline 40 & Omar Aziz & http://www.omar33.can.br/ & PMN & Manaus & 39,3 \\
\hline
\end{tabular}

142 REVISTA DEBATES, Porto Alegre, v. 5, n. 2, p. 117-144, jul.-dez. 2011. 


\begin{tabular}{|c|c|c|c|c|c|}
\hline 41 & Ricardo Coutinho & http://www.ricardocoutinho40.com.br/ & PPS & João Pessoa & 39,3 \\
\hline 42 & João & http://joao15.can.br/site/ & PMDB & Salvador & 39,3 \\
\hline 43 & Nelson Marchezan Junior & http://www.marchezan.com.br & PSDB & Porto Alegre & 38,7 \\
\hline 44 & Mario & http://www.mario13.can.br & PT & Belém & 37,3 \\
\hline 45 & Raul Filho & http://www.raulfilho13.can.br & PT & Palmas & 37,3 \\
\hline 46 & Luciana Genro & http://www.psolrs.org.br/lucianagenro/ & PSOL & Porto Alegre & 36,7 \\
\hline 47 & Reitor Moreira & http://www.reitormoreira15.can.br/ & PMDB & Curitiba & 36,7 \\
\hline 48 & Luiz Gastão & http://luizgastao23.can.br & PPS & Fortaleza & 36,7 \\
\hline 49 & Patricia & http://www.patricia12.can.br & PDT & Fortaleza & 36,7 \\
\hline 50 & Imbassahy & http://www.imbassahy45.com.br/ & PSDB & Salvador & 36,7 \\
\hline 51 & Nazareno & http://www.nazareno13.can.br/ & PT & Teresina & 36,7 \\
\hline 52 & Pastor Neto & http://www.pastorneto20.can.br & PSC & Fortaleza & 36,0 \\
\hline 53 & Flavio Dino & http://www.flaviodino65.can.br & PCdoB & São Luiz & 36,0 \\
\hline 54 & Cicero Almeida & http://www.ciceroalmeida11.can.br/ & $\mathrm{PP}$ & Maceió & 36,0 \\
\hline 55 & Marcelo Lelis & [cf. site] & $\mathrm{PV}$ & Palmas & 35,3 \\
\hline 56 & Jorge Periquito & http://www.periquito28.com.br/ & PRTB & Belo Horizonte & 35,3 \\
\hline 57 & Nilmar Ruiz & [cf. site] & DEM & Palmas & 33,3 \\
\hline 58 & Luciano Rezende & www.lucianorezende.com.br/ & PPS & Vitória & 32,7 \\
\hline 59 & Vinicius Cordeiro & http://www.viniciuscordeiro.adv.br/ & PTB & Rio de Janeiro & 32,0 \\
\hline 60 & Renato Roseno & http://www.renatoroseno50.com.br & PSOL & Fortaleza & 31,3 \\
\hline 61 & João Coser & http://www.joao13.can.br/site/ & PT & Vitória & 31,3 \\
\hline 62 & Sandes Junior & http://www.sandesjunior11.can.br/ & $\mathrm{PP}$ & Goiania & 31,3 \\
\hline 63 & Jandira Feghali & www.jandira65.can.br/ & PCdoB & Rio de Janeiro & 30,7 \\
\hline 64 & Almeida & [cf. site] & PMDB & Aracaju & 30,7 \\
\hline 65 & Dario & http://www.dario15.can.br & PMDB & Florianópolis & 30,0 \\
\hline 66 & Iris & http://www.iris15.can.br/ & PMDB & Goiania & 29,3 \\
\hline 67 & Fatima & http://fatima13natal.blogspot.com & PT & Natal & 28,7 \\
\hline 68 & Henrique Martini & http://www.henriquemartini50.can.br/ & PSOL & Campo Grande & 28,0 \\
\hline 69 & Wober Junior & http://www.vober23.can.br & PPS & Natal & 27,3 \\
\hline 70 & Roberto Numeriano & http://www.robertonumeriano.com/publicacoes.htm & PCB & Recife & 27,3 \\
\hline 71 & Afranio Boppré & http://www.afranio.org/ & PSOL & Florianópolis & 27,3 \\
\hline 72 & Gastão Vieira & http://www.gastaovieira15.can.br & PMDB & São Luiz & 26,7 \\
\hline 73 & Edmilson Costa & http://www.edmilsoncosta21.can.br/prefeito/ & PCB & São Paulo & 26,7 \\
\hline 74 & Praciano & http://www.praciano13.can.br/ & $\mathrm{PT}$ & Manaus & 26,7 \\
\hline 75 & Gustavo Valadares & http://www.gustavovaladares25.can.br/ & DEM & Belo Horizonte & 26,0 \\
\hline 76 & Paulo Ramos & http://www.deputadopauloramos.com.br/ & PDT & Rio de Janeiro & 26,0 \\
\hline 77 & Roberto Sobrinho & http://www.robertosobrinho13.can.br/ & PT & Porto Velho & 26,0 \\
\hline 78 & Marcelo Crivella & http://www.marcelocrivella.com.br/ & PRB & Rio de Janeiro & 25,3 \\
\hline 79 & Silvio Mendes & www.silviomendes45.can.br & PSDB & Teresina & 25,3 \\
\hline 80 & Priante & http://www.priante15.can.br & PMDB & Belém & 24,7 \\
\hline 81 & Onyx & http://www.onyx25.can.br/ & DEM & Porto Alegre & 24,7 \\
\hline 82 & Solange Jurema & http://www.solangejurema45.can.br/ & PSDB & Maceió & 24,7 \\
\hline 83 & Pedro Fernandes & http://www.pedrofernandes14.can.br & PTB & São Luiz & 23,3 \\
\hline
\end{tabular}




\section{DOSSIÊ OPINIÃO PÚBLICA, ELEIÇÕES E PARTICIPAÇÃO POLÍTICA NAS DEMOCRACIAS CONTEMPORÂNEAS}

\begin{tabular}{|l|l|l|l|l|l|}
\hline $\mathbf{8 4}$ & lara Costa & www.iaracosta33.can.br & PMN & Campo Grande & 23,3 \\
\hline $\mathbf{8 5}$ & Walter Rabello & http://www.walterrabello11.can.br/ & PP & Cuiabá & 22,7 \\
\hline $\mathbf{8 6}$ & Andre & www.andre.can.br & PTdoB & Belo Horizonte & 22,7 \\
\hline $\mathbf{8 7}$ & Edilson Sllva & http://edilson50.blogspot.com/ & PSOL & Recife & 22,7 \\
\hline $\mathbf{8 8}$ & Levy Fidelix & http://www.levyfidelix28.can.br & PRTB & São Paulo & 22,0 \\
\hline $\mathbf{8 9}$ & Serafim Correa & http://www.serafimcorrea40.can.br/ & PPS & Manaus & 22,0 \\
\hline $\mathbf{9 0}$ & Eduardo Serra & http://www.eduardoserra21.can.br/ & PCB & Rio de Janeiro & 21,3 \\
\hline $\mathbf{9 1}$ & Anaí Caproni & http://www.pco.org.br/ anaicaproni/index.html & PCO & São Paulo & 20,7 \\
\hline $\mathbf{9 2}$ & Waldir Maranhão & http://www.waldirmaranhao11.can.br & PP & São Luiz & 20,0 \\
\hline $\mathbf{9 3}$ & Felipe Pereira & http://www.filipepereira20.can.br/ & PSC & Rio de Janeiro & 20,0 \\
\hline $\mathbf{9 4}$ & Adahil Barreto & http://www.adahilbarreto22.can.br & PR & Fortaleza & 20,0 \\
\hline $\mathbf{9 5}$ & Roberto Goes & http://www.robertogoes12.can.br/ & PDT & Macapá & 19,3 \\
\hline $\mathbf{9 6}$ & Doutor Alexandre & http://www.doutoralexandre36.can.br/ & PTC & Porto Velho & 19,3 \\
\hline $\mathbf{9 7}$ & João Gonçalves & http://joaogoncalves45.can.br/ & PSDB & João Pessoa & 19,1 \\
\hline $\mathbf{9 8}$ & Sergio Miranda & http://www.sergiomiranda12.can.br/ & PDT & Belo Horizonte & 18,7 \\
\hline $\mathbf{9 9}$ & Carlinhos & http://www.carlinhos21.can.br & PCB & Fortaleza & 18,7 \\
\hline $\mathbf{1 0 0}$ & Joanilson Rego & http://www.joanilson27.can.br & PSDC & Natal & 16,7 \\
\hline
\end{tabular}

Fonte: Base de dados sobre eleições online do Grupo de Pesquisa Instituições, Comportamento Político e Novas Tecnologias (GEIST), da UFPR.

Texto recebido em 26/08/2011. Aprovado em 07/12/2011. 